\title{
Oral Immunization of Common Carp with a Liposome Vaccine Fusing Koi Herpesvirus Antigen
}

\author{
Shinya Yasumoto ${ }^{1}$, Yoshitaka Kuzuya', Masahiro Yasuda, \\ Tetsuro Yoshimura ${ }^{2}$ and Teruo Miyazaki ${ }^{1 *}$ \\ ${ }^{1}$ Graduate school of Bioresouces, Mie University, Tsu, Mie 514-8507, Japan \\ ${ }^{2}$ Graduate school of Engineering, Mie University, Tsu, Mie 514-8507, Japan
}

(Received May 26, 2006)

\begin{abstract}
In this study, we made liposome vaccines in which formalin-inactivated koi herpesvirus (KHV) was entrapped within the liposomal membrane compartment for oral vaccination in common carp Cyprinus carpio. In vaccination experiments, two fish groups (mean body weight, $30 \mathrm{~g}$ ) received the liposome vaccine (protein concentration of $20 \mu \mathrm{g} / \mathrm{mL}$ using an isolate of NKC03 from Nara Prefecture or an isolate of IKC03 from Ibaraki Prefecture) at a dose of $20 \mu \mathrm{L} /$ fish/day for 3 days. Neutralization titers of vaccinated fish sera were significantly higher than control at 22 days after last vaccination. In addition, 22 days after last vaccination, the fish were challenged with NKC03 at $10^{2.3} \mathrm{TCID}_{50} / 100 \mu \mathrm{L} /$ fish or $1 \mathrm{KCO} 03$ at $10^{2.2} \mathrm{TCID}_{50} / 100 \mu \mathrm{L} /$ /ish by dropping the inoculum onto their gills, and resulted RPS was $74.4 \%$ and $65.0 \%$, respectively. These results proved the efficacy of oral vaccination with the KHV liposome vaccine against KHV infection in carp.
\end{abstract}

Key Words: koi herpesvirus, KHV, liposome vaccine, oral vaccination, Cyprinus carpio.

Koi herpesvirus (KHV) is an emergent herpesvirus that infects only carp Cyprinus carpio. It has been causing mass mortalities with vast economic losses in Japan as well as USA, Israel, European countries, Asian and African countries since 1998 (Hedrick et al., 2000; Neukirch and Kunz, 2001; Perelberg et al., 2003; Ronen et al., 2003; Haenen et al., 2004; Sano et al., 2004; Schlotfeldt, 2004; Tu et al., 2004). There is an urgent need for a vaccine to prevent KHV infection. A live vaccine using attenuated KHV was developed for intramuscular injection (Ronen et al., 2003). There is a risk that the live vaccine might mutate to a highly virulent virus. Moreover, vaccination by injection is time- and labor-intensive and subjects fish to severe stress by handling. Oral vaccination is a more practical method because it requires little labor and causes no stress to fish. Oral administration of a liposome vaccine containing inactivated Aeromonas hydrophila antigens has been shown to induce immunity in carp (Yasumoto et al., 2006).

The goal of the present study was to develop an oral vaccine to immunize carp against KHV infection. We

\footnotetext{
* Corresponding author

E-mail: miyazaki@bio.mie-u.ac.jp
}

made a liposome vaccine in which inactivated KHV was entrapped within the liposomal membrane compartment. We evaluated production of serum-specific antibodies in orally vaccinated fish and protection of the vaccinated fish from artificial KHV infection.

\section{Materials and Methods}

\section{Liposome vaccine preparation}

In the present study, two KHV isolates (NKC03 from Nara Prefecture and IKC03 from Ibaraki Prefecture that was kindly donated by Dr. H. Fukuda, Tokyo University of Marine Science and Technology) were provided. The KHV isolates were cultured using KF-1 cells donated by Dr. R. P. Hedrick (University of California Davis) according to Hedrick et al. (2000). After fragmentation of all KHV-infected cells, cultured KHV was inactivated with formalin at a final concentration of $0.3 \%$ $(\mathrm{v} / \mathrm{v})$ and allowed to stand for $48 \mathrm{~h}$ at $24^{\circ} \mathrm{C}$. Cellular debris was removed by centrifugation at $3,000 \times g$ for 15 min and filtration $(450 \mathrm{~nm})$. Moreover, the inactivated $\mathrm{KHV}$ was collected by ultra-centrifugation at $200,000 \times g$ for $60 \mathrm{~min}$ and the obtained pellet was resuspended in phosphate-buffered saline (PBS, pH 7.2). The collected KHV was washed three times by ultra-centrifuga- 
tion to remove formalin. The resulting pellet of inactivated $\mathrm{KHV}$ was used as an antigen.

Before making liposomes, the KHV antigen was adjusted to a protein concentration of $20 \mu \mathrm{g} / \mathrm{mL}$. Protein concentration was determined using a Bio-Rad protein assay kit (Bio-Rad Laboratories, USA) with bovine plasma gamma globulin used as a standard. Liposomes fusing KHV antigen in the liposomal membrane compartment were prepared according to Yasumoto et al. (2006). The prepared liposomes were stored at $4^{\circ} \mathrm{C}$ and were sprayed onto porous drypelletted diets (Nippon Formula Feed) (hereafter pelleted diets), and dried for $5 \mathrm{~min}$ before feeding the pelleted diets to the fish.

\section{Experimental fish}

Common carp (mean body weight, $30 \mathrm{~g}$ ) were obtained from Ono Limnological Laboratory of National Fisheries University. All fish were offspring of the same parental fish. The fish were held in tanks with a watercirculation system at $24^{\circ} \mathrm{C}$ and were trained to feed on pelleted diets for 2 wk before starting the experiments.

\section{Uptake of liposomes in the epithelial cells of the posterior intestine}

In order to examine the uptake of liposomes containing $\mathrm{KHV}$ antigens in the intestine of carp, we also made liposomes containing FITC-labeled KHV. FITClabeled KHV was made by adding FITC dissolved in acetone to the inactivated IKC03 suspension and then kept the suspension at room temperature for $1 \mathrm{~h}$. An excess amount of lysine- $\mathrm{HCl}$ was added, and the resulting FITClysine was removed by ultra-centrifugation.

Two fish were orally administered with a $100 \mu \mathrm{L}$ suspension of liposomes containing FITC-labeled IKC03 by using a catheter. After $6 \mathrm{~h}$, the posterior intestine was removed and fixed in 10\% phosphate buffered formalin solution and stored at $4^{\circ} \mathrm{C}$. The fixed specimens were routinely embedded in O.C.T. Compound (Sakura Seiki, Japan) and sectioned with a cryostat (Bright, UK). These sections were observed with a laser scan microscope (Carl Zeiss, Germany).

\section{Vaccination}

Fish were fed on pelleted diets containing the liposome fusing $\mathrm{KHV}$ antigen (NKCO3 or IKC03) at $20 \mu \mathrm{L}$ liposome vaccine/fish/day for 3 days. Unvaccinated fish received just normal pelleted diets during the same days. Then, normal pelleted diets were given to all of the fish for the following 21 days.

\section{Serum antibody assays}

At 22 days after last vaccination (d.a.v.), the blood $(0.5 \mathrm{~mL})$ was taken from the caudal vein of each fish with a $1-\mathrm{mL}$ syringe while fish were anesthetized with $1.5 \%$ carbamic acid ethyl ester. The blood was allowed to clot at room temperature for $1 \mathrm{~h}$, and then kept at $4^{\circ} \mathrm{C}$ for $3 \mathrm{~h}$. The sera were then separated by centrifugation at $3,000 \times g$ for $15 \mathrm{~min}$ and stored at $-20^{\circ} \mathrm{C}$. The sera were heat inactivated at $56^{\circ} \mathrm{C}$ for $30 \mathrm{~min}$, 2-fold serially diluted with EMEM (Nissui, Japan) containing 2\% FBS (SIGMA, USA), and mixed with NKC03 $\left(10^{3.3} \mathrm{TCID}_{50} / 50\right.$ $\mu \mathrm{L})$ or IKC03 $\left(10^{3.2} \mathrm{TCID}_{50} / 50 \mu \mathrm{L}\right)$ at a $1: 1 \mathrm{v} / \mathrm{v}$ ratio. After incubation at $20^{\circ} \mathrm{C}$ for $1 \mathrm{~h}, 100 \mu \mathrm{L}$ of each dilution was added to KF-1 cells in a 96-well tissue culture plate (Corning, USA). Neutralization titers of anti-sera were determined by microscopic observation. All of the obtained data were statistically analyzed and evaluated using Student's $t$-test.

\section{Artificial infection}

From our histopathological study, KHV primarily invaded respiratory epithelial cells of gill (data not shown). We attempted a novel infection method, in which KHV was inoculated onto gills as described below. Fish was challenged by putting a $100 \mu \mathrm{L}$ $\mathrm{NKCO3}$ or IKCO3 suspension onto their gills. NKC03 was inoculated at $10^{3.3}, 10^{2.3}$ and $10^{1.3} \mathrm{TCID}_{50} / 100 \mu \mathrm{L}$ (n $=5$ each). IKC03 was inoculated at $10^{3.2}, 10^{2.2}$ and $10^{1.2} \mathrm{TCID}_{50} / 100 \mu \mathrm{L}(\mathrm{n}=10$ each). Fish were wrapped with wet papers and kept in the air for 5 min to complete $\mathrm{KHV}$ adhesion to gill cells and then returned to the tanks. KHV-inoculated fish were observed onset of KHV disease and mortality for 21 days. To confirm $\mathrm{KHV}$ infection, the gills and the kidneys were removed from all of the moribund fish to check for KHV DNA by PCR (Yuasa et al., 2005).

\section{Challenge test}

Based on the results from artificial infection, we set the challenge doses at $10^{2.3} \mathrm{TCID}_{50} / 100 \mu \mathrm{L}$ for NKC03 and $10^{2.2} \mathrm{TCID}_{50} / 100 \mu \mathrm{L}$ for IKC03 in challenge test. Fish were challenged with live $\mathrm{NKCO} 3$ or IKC03 by our novel method at 22 d.a.v.. Mortalities were recorded daily for the following 23 days. Each day moribund and dead fish were removed. All of the surviving fish were sacrificed at the end of the experiment. The gills and the kidneys were removed from all of the fish, and stored at $-80^{\circ} \mathrm{C}$ for PCR assay (Yuasa et al., 2005) and reisolation of live KHV using KF-1 cells. The protection of vaccinated fish against $\mathrm{KHV}$ was evaluated as the relative percent survival $(\mathrm{RPS}=(1-$ vaccinated group mortality/control group mortality) $\times 100)$ (Amend, 1981) and evaluated using Fisher's exact test.

\section{Results}

Uptake of liposomes in the epithelial cells of the posterior intestine

Confocal fluorescence microscopy revealed uptake of a large number of liposomes containing FITC-labeled $\mathrm{KHV}$ in the epithelial cells of the posterior intestine (Fig. 1). 


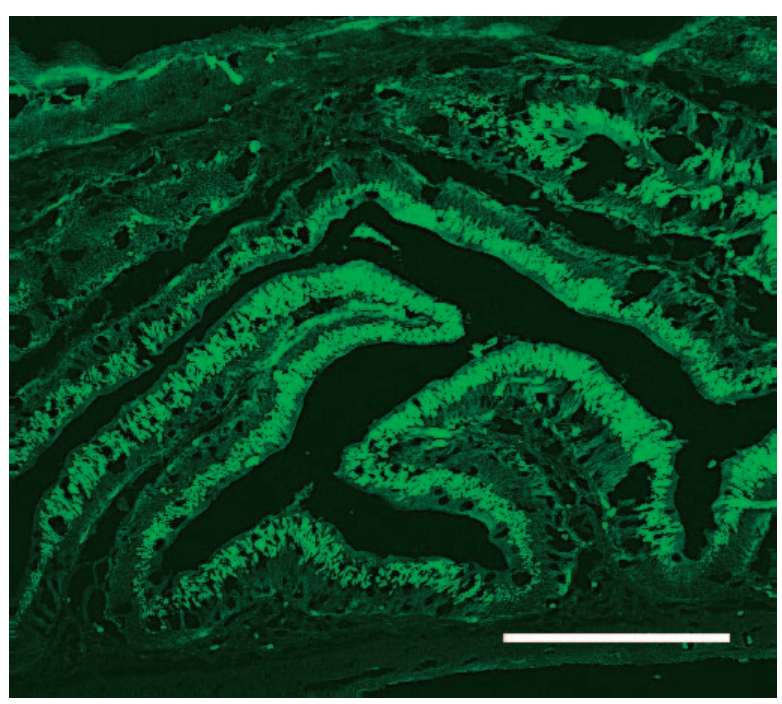

Fig. 1. FITC-labeled KHV in the posterior intestine. Image was obtained with a laser scan microscope. Scale bar = $200 \mu \mathrm{m}$.

\section{Antibody response}

The serum antibody titers of fish orally administrated with a liposome fusing NKC03 $(n=5)$ or IKC03 $(n=10)$ $\left(2^{5.9 \pm 1.0}\right.$ or $2^{5.7 \pm 0.9}$, respectively) were significantly higher $(p<0.01)$ than those of control groups $(\mathrm{n}=5$ or $\mathrm{n}=10$, respectively) $\left(2^{3.4 \pm 0.5}\right.$ or $2^{3.6 \pm 0.7}$, respectively $)$.

\section{Artificial infection}

Our novel method clearly induced dose responses in mortality. Mortality was increased with increase of dosage of $\mathrm{NKCO} 3$ and IKC03, reaching $100 \%$ at doses of $10^{3.3} \mathrm{TCID}_{50} / 100 \mathrm{~mL}$ and $10^{3.2} \mathrm{TCID}_{50} / 100 \mu \mathrm{L}$, respectively. The mortality caused by $\mathrm{NKC03}$ was $80 \%$ at $10^{2.3} \mathrm{TCID}_{50} / 100 \mu \mathrm{L}$ and $40 \%$ at $10^{1.3} \mathrm{TCID}_{50} / 100$ $\mu \mathrm{L}$. In the case of $\mathrm{IKC03}$, the resulted mortality was $70 \%$ at $10^{2.2} \mathrm{TCID}_{50} / 100 \mu \mathrm{L}$ and $30 \%$ at $10^{1.2} \mathrm{TCID}_{50} / 100$ $\mu \mathrm{L}$. The moribund and dead fish showed definite changes of gill tissues (data not shown). Putative PCR amplicons were derived from DNA extracts from the gills and the kidneys of all moribund fish (data not shown). These results validated our novel method for $\mathrm{KHV}$ inoculation.

\section{Challenge test}

In vaccinated fish with NKC03 liposome vaccine (n = 13), which was challenged with NKC03 at $10^{2.3} \mathrm{TCID}_{50} /$ $100 \mu \mathrm{L}$, three fish died within 7-11 days post challenge (d.p.c.) and the cumulative mortality was $23.1 \%$ (3/13 fish) by 23 d.p.c.. On the other hand, in unvaccinated fish $(n=10)$, nine fish died, and the cumulative mortality was $90.0 \%$ (9/10 fish) by 23 d.p.c. (Fig. 2). Relative percent survival (RPS) was $74.3 \%$.

In vaccinated fish with IKC03 liposome vaccine $(n=$ 30 ), which was challenged with IKC03 at $10^{2.2} \mathrm{TCID}_{50} /$ $100 \mu \mathrm{L}$, seven fish died and the cumulative mortality was 23.3\% (7/30 fish) by 23 d.p.c. (Fig. 2). On the other hand, In unvaccinated fish $(\mathrm{n}=30), 20$ fish died, and the cumulative mortality was $66.7 \%$ (20/30 fish) by 23 d.p.c. (Fig. 2). RPS was $65.0 \%$.

The moribund fish displayed many swollen cells in the gill epithelium, while all of the survivors showed no obvious changes in their gills.

Putative PCR amplicons were derived from DNA extracts of the gills and the kidneys of all moribund fish in vaccinated group and unvaccinated group (Table 1). Moreover, KHV was reisolated from all the gills and kidneys of the representative moribund fish, indicating

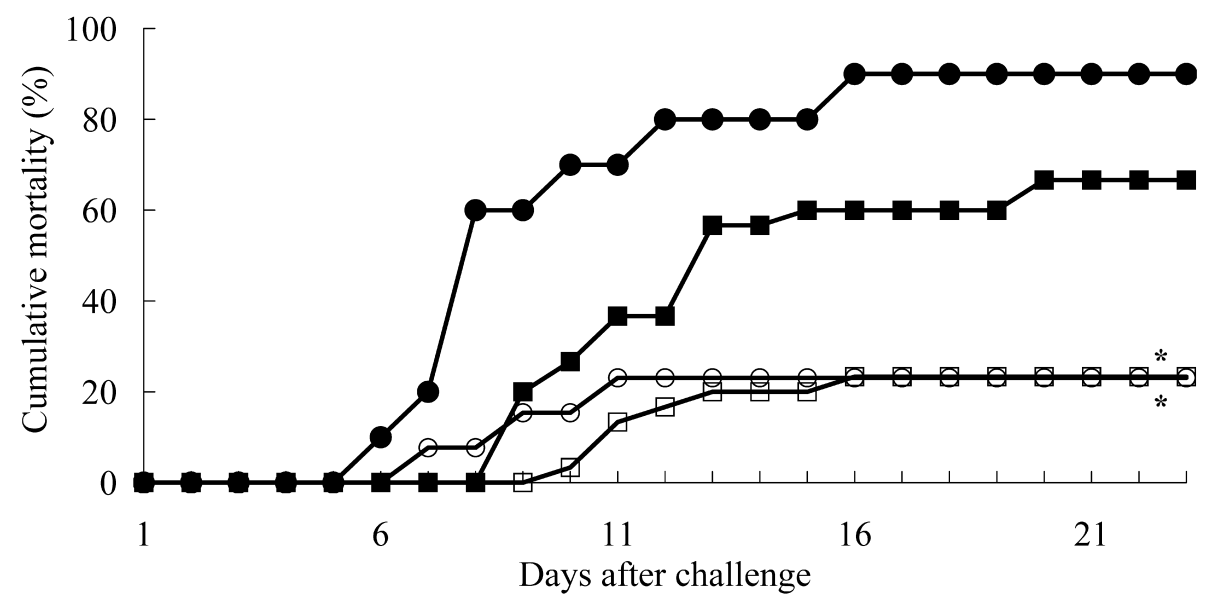

Fig. 2. Mortalities in orally vaccinated fish. Fish $(O ; n=13$ or $\square ; n=30)$ were orally administrated with a liposome vaccine containing $\mathrm{KHV}$ isolate $\mathrm{NKC03}$ or IKC03, respectively, at $20 \mathrm{~mL}$ liposome vaccine/fish/day for 3 days, and fish $(\boldsymbol{\bullet} ; n=10$ or $\mathbf{\square} ; n=$ 30) were used as control. Fish $[(\bigcirc$ and $\bullet)$ or $(\square$ and $\mathbf{\square})]$ were challenged with live NKC03 at $10^{2.3} \operatorname{TCID}_{50} / 100 \mu \mathrm{L} /$ fish or live IKC03 at $10^{2.2} \operatorname{TCID}_{50} / 100 \mu \mathrm{L}$ /fish, respectively, onto their gills 22 days after last vaccination. *: Significantly difference from control $(p<0.01)$. 
Table 1. PCR result of fish in challenge tests

\begin{tabular}{|c|c|c|c|c|c|c|c|}
\hline \multirow{2}{*}{$\mathrm{KHV}$ isolate } & \multirow{2}{*}{ Group } & \multirow{2}{*}{ Fish } & \multirow{2}{*}{$\begin{array}{c}\text { Total } \\
\text { No. of fish }\end{array}$} & \multicolumn{3}{|c|}{ No. of fish } & \multirow[b]{2}{*}{$\mathrm{G}-, \mathrm{K}-$} \\
\hline & & & & $\mathrm{G}+, \mathrm{K}_{+}^{\mathrm{a}}$ & $\mathrm{G}+, \mathrm{K}-$ & $\mathrm{G}-, \mathrm{K}+$ & \\
\hline \multirow[t]{4}{*}{ NKC03 } & Vaccinated & dead, moribund & 3 & 3 & 0 & 0 & 0 \\
\hline & & surviving & 10 & 1 & 1 & 0 & 8 \\
\hline & Control & dead, moribund & 9 & 9 & 0 & 0 & 0 \\
\hline & & surviving & 1 & 0 & 0 & 0 & 1 \\
\hline \multirow[t]{4}{*}{ IKC03 } & Vaccinated & dead, moribund & 7 & 7 & 0 & 0 & 0 \\
\hline & & surviving & 23 & 2 & 2 & 2 & 17 \\
\hline & Control & dead, moribund & 20 & 20 & 0 & 0 & 0 \\
\hline & & surviving & 10 & 2 & 1 & 3 & 4 \\
\hline
\end{tabular}

a: G, gill; K, kidney; +, PCR-positive; -, PCR-negative

that they died of KHV infection.

Out of 23 survivors in vaccinated fish with $\mathrm{IKCO} 3$ liposome vaccine, six were KHV-positive at gills and/or kidneys by PCR. We tried to reisolate KHV from the six surviving fish. CPE was observed in $\mathrm{KF}-1$ cells inoculated with a filtrate from one of the gill samples but not in the cells inoculated with the other samples. Furthermore, no CPE was observed in cells after an additional blind passage. As a result, only one of the surviving vaccinated fish was determined to hold live $\mathrm{KHV}$ in gill tissue.

\section{Discussion}

In the present study, based on our previous studies that fish take up crude lipids in the posterior intestine (Miyazaki and Fujiwara, 1988), we prepared a liposome vaccine entrapping KHV antigens that was designed to be taken up in the posterior intestine via oral route. Confocal fluorescence microscopy revealed the uptake of a large number of liposomes containing FITC-labeled $\mathrm{KHV}$ without digested in the epithelial cells of the posterior intestine. Thus, the KHV antigens entrapped in liposomes were absorbed in the posterior intestine, resulting in a stimulation of the immune systems followed by inducing antibody production and protective immunity.

Oral administration of the KHV liposome vaccine for 3 days significantly raised the serum KHV antibody titer after 21 days. However, unvaccinated control fish had the natural KHV antibody. Although the titer was as low as $2^{3.4-3.6}$, it was unneglectable. The same natural KHV antibody was found in normal carp cultured in Israel (Ronen et al. 2003). According to the study by Adkinson et al. (2005), in the United State, normal carp have a low titer of anti-CyHV-1 (Cyprinid herpesvirus 1) antibody cross-reacting with KHV. In the present study, the low titer of serum CyHV-1 antibody that was naturally present in unvaccinated carp is supposed to cross-react with $\mathrm{KHV}$ and, therefore, be detected as the KHV antibody.

In previous infection experiments with $\mathrm{KHV}$, cohabi- tation with diseased fish and virus immersion were applied (Ronen et al. 2003; Adkinson et al. 2005; StHilaire et al. 2005). However, by these methods, it is not known exactly how many KHV invade fish. Based on the histopathological findings that KHV primary infect cells of the gills, we designed a new method in which $\mathrm{KHV}$ were inoculated onto gills out of the water Results obtained in the experiments displayed the clear dosedependence of mortality and reproduction of definite pathological signs. Therefore, we determined that our novel infection method is the most suitable method for artificial infection of KHV.

Two challenge tests with the novel infection method using isolates of $\mathrm{NKCO}$ and IKCO3 revealed that orally vaccinated fish were immunized and protected from artificial infection with the homo-isolate, resulting in high RPS. These results indicate that the efficacy of immunization with the liposome vaccine is reproducible. Moreover, in the PCR assay, KHV DNA was not detected in most of the surviving vaccinated fish (6/23), while it was detected in $60 \%(6 / 10)$ of the surviving unvaccinated fish. The results of the challenge tests and PCR assay confirm the efficacy of oral vaccination with the KHV liposome vaccine in carp.

A live vaccine using attenuated $\mathrm{KHV}$ was found to induce an immune response in common carp (Ronen et al. 2003). There is a risk that the live attenuated vaccine might re-gain virulence through mutation, whereas $\mathrm{KHV}$ liposome vaccine developed in this study never has such a risk.

\section{Acknowledgements}

We thank Dr. H. Fukuda (Tokyo University of Marine Science and Technology) for donating an experimental KHV isolate. We thank Dr. R. Hedrick (University of California Davis) for donating KF-1 cells. We also thank Dr. Y. Takahashi and Dr. M. Kondo (Department of Applied Aquabiology National Fisheries University) for providing the experimental carp. This study was supported by a grant from the Japan Science and Technology Agency. 


\section{References}

Adkinson, M. A., O. Gilad and R. P. Hedrick (2005): An enzyme linked immunosorbent assay (ELISA) for detection of antibodies to the koi herpesvirus (KHV) in the serum of koi Cyprinus carpio. Fish Pathol., 40, 53-62.

Amend, D. F. (1981): Potency testing of fish vaccines. In "Fish biologics: serodiagnostics and vaccines" (ed. by D. P. Anderson and W. Hennessen). Karger, Geneva, pp. 447454.

Haenen, O. L. M., K. Way, S. M. Bergmann and E. Ariel (2004): The emergence of koi herpesvirus and significance to European aquaculture. Bull. Euro. Assoc. Fish Pathol. 24, 293-307.

Hedrick, R. P., O. Gilad, S. Yun and J. V. Spangenberg (2000): A herpesvirus associated with mass mortality of juvenile and adult koi, a strain of a common carp. J. Aquat. Anim. Health, 12, 44-57.

Miyazaki, T. and K. Fujiwara (1988): Histological studies on yolk utilization and digestive function in larvae and juvenile of red sea bream and black sea bream. Bull. Fac. Bioresous Mie Univ., 1, 15-27. (in Japanese with English abstract)

Neukirch M. and U. Kunz (2001): Isolation and preliminary characterization of several viruses from koi (Cyprinus carpio) suffering gill necrosis and mortality. Bull. Eur. Assn. Fish Pathol., 21, 125-135.

Perelberg, A., M. Smirnov, M. Hutoran, A. Diamant, Y. Bejerano and M. Kotler (2003): Epidemiological description of a new viral disease affecting cultured Cyprinus carpio in Israel. Israel J. Aquacult., 55, 5-12.

Ronen, A., A. Perelberg, J. Abramowitz, M. Hutoran, S. Tinman, I. Bejerano, M. Steinitz and M. Kotler (2003): Efficient vaccine against the virus causing a lethal disease in cultured Cyprinus carpio. Vaccine 21, 4677-4684.

Sano, M., T. Ito, J. Kurita, T. Yanai, N. Watanabe, S. Miwa and T. lida (2004): First detection of koi herpesvirus in cultured common carp Cyprinus carpio in Japan. Fish Pathol., 39, $165-167$.

Schlotfeldt, H. F. (2004): Severe losses of common carp in Germany due to koi herpesvirus (KHV). Bull. Euro. Assoc. Fish Pathol., 24, 216-217.

St-Hilaire, S., N. Beevers, K. Way, R. M. L. Deuff, P. Martin, C. Joiner (2005): Reactivation of koi herpesvirus infections in common carp Cyprinus carpio. Dis. Aquat. Org., 67, 1523.

Tu, C., M. C. Weng, J. R. Shiau and S. Y. Lin (2004): Detection of koi herpesvirus in koi Cyprinus carpio in Taiwan. Fish Pathol. 39, 109-110.

Yasumoto, S., T. Yoshimura and T. Miyazaki (2006): Oral immunization of common carp with a liposome vaccine containing Aeromonas hydrophila antigen. Fish Pathol., 41, 45-49.

Yuasa, K., M. Sano, J. Kurita, T. Ito and T. lida (2005): Improvement of a PCR method with the Sph I-5 primer set for the detection of koi herpesvirus (KHV). Fish Pathol., 40, 3739. 